\title{
Administration of Duddingtonia flagrans chlamydospores to goats to control gastro-intestinal nematodes: dose trials
}

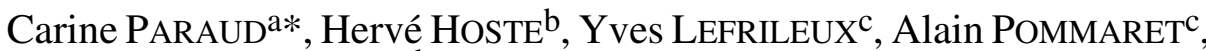 \\ Virginie PAOLINI ${ }^{\mathrm{b}}$, Isabelle PORS ${ }^{\mathrm{a}}$, Christophe CHARTIER ${ }^{\mathrm{a}}$ \\ a AFSSA Site de Niort, Laboratoire d'Études et de Recherches Caprines, 60 rue de Pied de Fond, \\ BP 3081, 79012 Niort Cedex, France \\ $\mathrm{b}$ Unité Mixte de Recherches 1225 INRA/DGER, Interactions Hôtes Pathogènes, \\ École Nationale Vétérinaire de Toulouse, 23 chemin des Capelles, 31076 Toulouse, France \\ c Station du Pradel, Ferme Expérimentale Caprine, 07170 Mirabel, France
}

(Received 3 May 2004; accepted 24 September 2004)

\begin{abstract}
The ability of the nematophagous fungus Duddingtonia flagrans to reduce the number of infective nematode larvae in coproculture was investigated in goats using different doses of chlamydospores $\left(0,1.25 \times 10^{5}, 2.5 \times 10^{5}, 5 \times 10^{5}\right.$ chlamydospores $/ \mathrm{kg} \mathrm{BW} /$ day $)$ given by oral administration or by voluntary consumption in feed during natural or experimental infections with nematodes. The kinetics of excretion of $D$. flagrans chlamydospores in the faeces was also determined using a dose of $5 \times 10^{5}$ chlamydospores $/ \mathrm{kg}$ BW/day for five days. For all the trials, the faecal nematode egg outputs were determined by a modified McMaster method and standard coprocultures were set up $\left(14\right.$ days, $\left.25^{\circ} \mathrm{C}\right)$ to determine the number of larvae emerging from culture in fungus treated and control faeces. When chlamydospores were orally administered, the number of larvae were reduced by 50 to $97 \%$ when compared to control cultures. No difference in the level of larval emergence from the culture was seen for experimental or natural infections at the different chlamydospore dose rates. In contrast, when chlamydospores were distributed in the feed, a dosedependent relationship was observed 10 days after the start of administration, the larval development being $2.0 \%, 14.0 \%$ and $86.9 \%$ for $5 \times 10^{5}, 2.5 \times 10^{5}$ and 0 spores $/ \mathrm{kg} \mathrm{BW} /$ day, respectively. In addition, the kinetic study showed that the larval emergence from coproculture in the fungus group was statistically lower than in the control group from the second day of administration of the chlamydospores and remained lower until the second day after the last administration $(p<0.05)$. The results indicate that, for goats in farm conditions, a minimum daily dose of $5 \times 10^{5}$ chlamydospores $/ \mathrm{kg}$ BW must be used to ensure a high treatment efficacy and that daily administration is preferable for maintenance of efficacy over time.
\end{abstract}

goat / biological control / Duddingtonia flagrans / nematode parasite / dose trials

\section{INTRODUCTION}

Drug resistant populations of nematodes in goats have reached a disturbing preva- lence. Two recent surveys conducted in Poitou-Charentes and Midi-Pyrénées in France $[5,6]$ reported that almost $100 \%$ of investigated farms presented nematodes

\footnotetext{
* Corresponding author: c.paraud@niort.afssa.fr
} 
resistant to benzimidazoles. On the other hand, organic farming where the use of chemicals is reduced is increasing in popularity due to consumer demands. These two points indicate that there is an urgent need to implement non-chemical solutions to control parasitism in dairy goats.

Alternative methods currently studied worldwide include the following [25]: grazing management, vaccination, manipulation of diets (protein supplementation, use of condensed tannins), selection of genetically resistant hosts or biological control using nematophagous fungi.

Administered as chlamydospores, the predacious fungus Duddingtonia flagrans has demonstrated its efficacy in reducing the pre-parasitic stages of gastro-intestinal nematodes in the faeces of several domestic species: horses [1], pigs [16], cattle [8] and sheep [10]. In goats, preliminary studies have shown that $D$. flagrans is able to reduce the number of larvae in coproculture of two of the predominant nematode species in France, Teladorsagia circumcincta and Trichostrongylus colubriformis by more than $80 \%$ in experimental studies $[17,18]$ and from 50 to $80 \%$ in a plot study [4]. Similarly, Terrill et al. [23] in the southeastern United States and Chandrawathani et al. [2] in Malaysia have demonstrated the capability of $D$. flagrans to limit the number of Haemonchus contortus infective larvae in faecal cultures in tropical conditions when varying the chlamydospore dose rates or fungal delivery systems.

These previous results were obtained with different levels of daily administration of chlamydospores to the animals and the optimal dose rate still remains to be determined for temperate nematode species, especially in field conditions. Different factors must be taken into account to choose the best dose rate. Firstly, the dose must be chosen to significantly and regularly reduce the level of larval emergence from the faeces in order to have a substantial impact on pasture contamination. In addition, the optimal dosage must minimize variability between animals due to fluctuations in voluntary ingestion when chlamydospores are distributed in feed by farmers. Finally, the minimum effective dose rate must be defined to limit the eventual environmental impact of releasing high quantities of chlamydospores in faecal material [12, 28].

The aim of this study was thus two-fold: firstly, to compare the efficacy of different dose rates of $D$. flagrans chlamydospores on the larvae of various nematode species in experimental conditions after oral administration or voluntary consumption in feed, and secondly, to measure the kinetics of chlamydospore excretion in faeces in order to determine whether daily or less frequent administration has to be recommended.

\section{MATERIALS AND METHODS}

\subsection{Efficacy studies}

\subsubsection{Experimentally infected goats with chlamydospores dosed orally}

Seven culled dairy goats were purchased from a private farm using a zero-grazing system. After checking they were free from gastrointestinal nematode infection, they were maintained on concrete floor and infected by Trichostrongylus colubriformis (7000 infective larvae per goat). They were then randomly divided into three groups of two goats according to the $D$. flagrans chlamydospore dose rate $\left(1.25 \times 10^{5}, 2.5 \times 10^{5}\right.$ or $5 \times 10^{5}$ chlamydospores/kg BW/day) and one goat remained untreated (control). The chlamydospores were dosed to individual goats by oral administration in an alimentary oil suspension for 20 days. In order to avoid the eventual fluctuation in chlamydospore excretion in faeces at the start of the experiment [26], the faeces were collected from each animal twice daily (morning and afternoon) only from day 10 to day 20 of administration. 


\subsubsection{Naturally infected animals with chlamydospores dosed orally}

Twelve naturally infected (Haemonchus contortus, Teladorsagia circumcincta and T. colubriformis) culled goats were maintained indoors and allocated to two groups of six animals, which were balanced according to the level of nematode egg excretion. They received the chlamydospores at either of two doses, $2.5 \times 10^{5}$ or $5 \times 10^{5}$ spores/ $\mathrm{kg}$ BW/day, administered orally with a syringe in a water suspension for 10 days. Individual faecal samples were collected before the first dose of chlamydospores (d0) and then 6 days (d6) and 10 days (d10) after the first dose.

\subsubsection{Naturally infected goats with chlamydospores in feed}

At dry-out, 45 goats naturally infected with gastrointestinal nematodes ( $T$. colubriformis and $T$. circumcincta) were allocated to three groups of 15 animals which were balanced according to the level of nematode egg excretion. The first group of goats received $D$. flagrans chlamydospores at the dose rate of $2.5 \times 10^{5}$ spores $/ \mathrm{kg} \mathrm{BW} /$ day, group 2 received $5 \times 10^{5}$ chlamydospores/kg BW/day and the last group remained as the untreated control. The chlamydospores were given daily for 10 days in feed by mixing with humidified barley grains and consumed before the distribution of the main diet. Individual faecal samples were collected directly per rectum two days before the first administration (d-2) and 6 (d6) and 10 days (d10) after the start of feeding the fungi. Individual faecal samples were also obtained from the three groups of goats 30 days (d30) after the start of fungi feeding, i.e. 20 days after the last treatment with fungus.

\subsubsection{The kinetics of excretion of chlamydospores and efficacy}

The activity of $D$. flagrans in faeces was assessed when starting or stopping the administration of chlamydospores to the animals. Four goats received the fungus $\left(5 \times 10^{5}\right.$ chlamydospores $/ \mathrm{kg} \mathrm{BW} /$ day) by oral dosing for 5 days while the other three goats acted as controls not receiving chlamydospores. Individual faecal samples were collected before the administration of spores on day 1 then on each day of administration (from day 2 to day 5) and for 5 days after the last administration (from day 6 to day 10).

\subsection{Fungal material}

The chlamydospores were provided by Christian Hansen Ltd., Denmark. They were produced on millet seeds and packaged in opaque bags that were conserved at $4{ }^{\circ} \mathrm{C}$ until use.

\subsection{Measurement of fungi efficiency}

The faecal nematode egg outputs were determined individually using a modified McMaster method with a sensitivity of 15 eggs per gram [20].

Five to $8 \mathrm{~g}$ of faeces from each goat and for each collection were then cultured for 14 days at $25{ }^{\circ} \mathrm{C}$ in a climatic chamber in small boxes. The cultures were aerated and slightly moistened twice a week.

At the end of the incubation period, the larvae from each faecal culture were collected using a Baermann technique for $24 \mathrm{~h}$ [7] and the third stage larvae were counted.

\subsection{Statistical analysis}

The data were expressed as mean egg output (epg) and larval output (lpg) per group. The percentage of development of larvae from the faecal samples of the different groups was calculated as the ratio between the total number of larvae and the total number of eggs in the faeces $\times 100$.

The percentage of reduction of larval development was calculated as (1 - (percentage of development in the fungus group/ percentage of development in the control group)) $\times 100$. 
Table I. Mean number of eggs per gram (epg), mean number of larvae per gram (lpg) and percentage of larval development obtained after coproculture $\left(14\right.$ days, $\left.25^{\circ} \mathrm{C}\right)$ in the control group and with three daily fungal doses (control group: $n=20$; other groups: $n=40$ ).

\begin{tabular}{lcccc}
\hline & Control group & $1.25 \times 10^{5}$ group & $2.5 \times 10^{5}$ group & $5 \times 10^{5}$ group \\
\hline Mean epg (SD) & $245^{\mathrm{a}}(61)$ & $243^{\mathrm{a}}(105)$ & $186^{\mathrm{b}}(72)$ & $243^{\mathrm{a}}(82)$ \\
Mean lpg (SD) & $55^{\mathrm{a}}(25)$ & $13^{\mathrm{b}}(14)$ & $20^{\mathrm{c}}(20)$ & $10^{\mathrm{b}}(12)$ \\
$\%$ of larval development & 22.4 & 5.3 & 10.8 & 4.1 \\
\hline
\end{tabular}

$1.25 \times 10^{5}$ group: goats receiving $1.25 \times 10^{5}$ chlamydospores $/ \mathrm{kg} \mathrm{BW} /$ day.

$2.5 \times 10^{5}$ group: goats receiving $2.5 \times 10^{5}$ chlamydospores $/ \mathrm{kg} \mathrm{BW} /$ day.

$5 \times 10^{5}$ group: goats receiving $5 \times 10^{5}$ chlamydospores $/ \mathrm{kg}$ BW/day.

$\mathrm{a}, \mathrm{b}, \mathrm{c}$ Different superscripts in a same row indicate a statistical difference between the groups $(p<0.05)$.

The comparison of epg and lpg variables was made using the non-parametric Mann and Whitney-test except when the egg excretions of the two groups were statistically different. In this case, the data were $\log$ transformed $(\operatorname{lpg}+1)$ and analysed by covariance analysis with the covariable being $\log ($ epg +1$)$.

Data analysis was performed using StatMost 2.5 for Windows (DataMost Corporation Salt Lake City, USA). The statistical significance of the variables was tested at the 0.05 level of confidence.

\section{RESULTS}

\subsection{Efficacy studies}

\subsubsection{Experimentally infected goats with chlamydospores dosed orally (Tab. I)}

There was no significant difference in the mean egg excretion between the control, the $1.25 \times 10^{5}$ and $5 \times 10^{5}$ groups. The mean egg excretion in the group receiving $2.5 \times 10^{5}$ chlamydospores $/ \mathrm{kg} \mathrm{BW/day} \mathrm{was}$ statistically lower than the egg excretion of the other groups $(p<0.001)$.

The larval development in the control group was $22 \%$. In the group receiving $1.25 \times 10^{5}$ chlamydospores $/ \mathrm{kg} \mathrm{BW} /$ day, the larval yield was statistically lower $(p<0.001)$ than the larval yield in the con- trol group and the reduction of the larval development compared to the control was $75 \%$. In the same way, the larval yield was statistically lower $(p<0.001)$ in the group receiving $5 \times 10^{5}$ chlamydospores $/ \mathrm{kg} \mathrm{BW/}$ day and the larval development reduction was $81 \%$ compared to the control. No difference was observed in the activity of $D$. flagrans between the dose rates of $1.25 \times 10^{5}$ and $5 \times 10^{5}$ chlamydospores $/ \mathrm{kg} \mathrm{BW}$.

The larval yield in the group receiving $2.5 \times 10^{5}$ chlamydospores $/ \mathrm{kg} \mathrm{BW/day} \mathrm{was}$ statistically different from the control and the two other groups. The larval yield was statistically lower $(p<0.001)$ than in the control group but higher compared $(p<0.05, p<0.05)$ to the $1.25 \times 10^{5}$ and $5 \times 10^{5}$ groups. The reduction in the percentage of larval development compared with the control was only $52 \%$.

\subsubsection{Naturally infected animals with chlamydospores dosed orally (Tab. II)}

There was no significant difference in the mean epg between the two groups nor on the different dates of measurement, nor between the dates for each group.

In the two experimental groups, a similar trend was observed in variations of values of larval production with time. The larval yield was identical for the two groups at each timepoint. 
Table II. Mean number of eggs per gram (epg) of faeces, mean number of larvae per gram (lpg) of faeces and percentage of larval development on days 0,6 and 10 after the beginning of distribution of the spores in two groups of naturally infected goats dosed with $2.5 \times 10^{5}$ or $5 \times 10^{5}$ chlamydospores of $D$. flagrans $/ \mathrm{kg}$ BW/day.

\begin{tabular}{lccc}
\hline & & $2.5 \times 10^{5}$ group & $5 \times 10^{5}$ group \\
\hline d0 & Mean epg (SD) & $1180^{\mathrm{a}, \mathrm{A}}(811)$ & $1108^{\mathrm{a}, \mathrm{A}}(998)$ \\
& Mean lpg (SD) & $374^{\mathrm{a}, \mathrm{A}}(337)$ & $263^{\mathrm{a}, \mathrm{A}}(271)$ \\
\% of larval development & 31.7 & 23.7 \\
Mean epg (SD) & $1130^{\mathrm{a}, \mathrm{A}}(1119)$ & $1425^{\mathrm{a}, \mathrm{A}}(1307)$ \\
& Mean lpg (SD) & $100^{\mathrm{a}, \mathrm{A}}(63)$ & $60^{\mathrm{a}, \mathrm{B}}(46)$ \\
& $\%$ of larval development & 8.8 & 4.2 \\
d10 & Mean epg (SD) & $1170^{\mathrm{a}, \mathrm{A}}(1165)$ & $1508^{\mathrm{a}, \mathrm{A}}(1453)$ \\
& Mean lpg (SD) & $23^{\mathrm{a}, \mathrm{B}}(14)$ & $69^{\mathrm{a}, \mathrm{B}}(69)$ \\
& $\%$ of larval development & 1.9 & 4.6 \\
\hline
\end{tabular}

$2.5 \times 10^{5}$ group: goats receiving $2.5 \times 10^{5}$ chlamydospores $/ \mathrm{kg}$ BW/day.

$5 \times 10^{5}$ group: goats receiving $5 \times 10^{5}$ chlamydospores $/ \mathrm{kg} \mathrm{BW} /$ day.

a,b Different superscripts in a same row indicate a significant difference between the doses $(p<0.05)$.

A,B Different capital letters in a same column indicate a significant difference between the tested day (d6 or $\mathrm{d} 10)$ and day $0(p<0.05)$.

For the group receiving $2.5 \times 10^{5}$ chlamydospores/kg BW/day, the larval yield at day 6 was the same as the larval yield on day 0 before the administration of chlamydospores. In contrast, in the group receiving $5 \times 10^{5}$ chlamydospores/kg BW/day, at day 6 , the larval yield was statistically lower $(p<0.05)$ than on day 0 . At day 10 , the larval yield was significantly lower $(p<0.05, p<0.05)$ than on day 0 for both groups.

Compared to the initial level of larval production, the distribution of $2.5 \times 10^{5}$ fungi was associated with a $94.0 \%$ reduction in the mean larval production on day 10 of fungi distribution. In the goats receiving the highest dose of fungi, that value was $80.5 \%$.

\subsubsection{Field study of naturally infected goats and administration of chlamydospores in feed (Tab. III)}

No statistical differences in mean epg were detected between the three groups at any timepoint.
No statistical differences in larval production were detected between the three groups of goats on day 0 and day 6 after the start of fungi distribution as well as 20 days after the end of fungi distribution. In contrast, on day 10 of distribution, the larval yield obtained from the faeces of goats receiving $5 \times 10^{5}$ chlamydospores $/ \mathrm{kg} \mathrm{BW}$ was statistically lower $(p<0.01)$ than the larval yield issued from the goats receiving the $2.5 \times 10^{5}$ chlamydospores $/ \mathrm{kg} \mathrm{BW}$ as well as those from the control goats. The larval reductions were $83.9 \%$ and $97.7 \%$ for the goats receiving $2.5 \times 10^{5}$ chlamydospores $/ \mathrm{kg} \mathrm{BW/day} \mathrm{and} 5 \times 10^{5}$ chlamydospores/kg BW/day, respectively, when compared with the control group.

\subsection{Kinetics of excretion of chlamydospores in faeces (Tab. IV)}

There was no significant difference in the mean epg between the control and fungus group, except the 2nd day of administration of the fungus when the egg excretion 
Table III. Mean number of eggs per gram (epg) of faeces, mean number of larvae per gram (lpg) of faeces and percentage of larval development in three groups of naturally infected goats receiving a daily dose of 0 (control), $2.5 \times 10^{5}$ or $5 \times 10^{5}$ chlamydospores of $D$. flagrans $/ \mathrm{kg} \mathrm{BW}$ in feed, on day 0,6 and 10 after the feeding started and 20 days (d30) after feeding stopped.

\begin{tabular}{|c|c|c|c|c|}
\hline & & Control group & $2.5 \times 10^{5}$ group & $5 \times 10^{5}$ group \\
\hline \multirow[t]{3}{*}{ d0 } & Mean epg (SD) & $199^{\mathrm{a}}(154)$ & $230^{\mathrm{a}}(140)$ & $239^{\mathrm{a}}(174)$ \\
\hline & Mean lpg (SD) & $80^{\mathrm{a}}(96)$ & $37^{\mathrm{a}}(33)$ & $71^{a}(109)$ \\
\hline & $\%$ of larval development & 40.0 & 16.3 & 29.6 \\
\hline \multirow[t]{3}{*}{ d6 } & Mean epg (SD) & $135^{\mathrm{a}}(100)$ & $153^{\mathrm{a}}(84)$ & $116^{\mathrm{a}}(93)$ \\
\hline & Mean lpg (SD) & $40^{\mathrm{a}}(40)$ & $29^{\mathrm{a}}(23)$ & $21^{\mathrm{a}}(24)$ \\
\hline & $\%$ of larval development & 29.9 & 19.2 & 17.6 \\
\hline \multirow[t]{3}{*}{$\mathrm{d} 10$} & Mean epg (SD) & $124^{\mathrm{a}}(104)$ & $139^{\mathrm{a}}(128)$ & $141^{\mathrm{a}}(112)$ \\
\hline & Mean lpg (SD) & $107^{\mathrm{a}}(68)$ & $19^{\mathrm{b}}(20)$ & $3^{\mathrm{c}}(4)$ \\
\hline & $\%$ of larval development & 86.9 & 14.0 & 2.0 \\
\hline \multirow[t]{3}{*}{$\mathrm{d} 30$} & Mean epg (SD) & $151^{\mathrm{a}}(79)$ & $197^{\mathrm{a}}(97)$ & $193^{\mathrm{a}}(139)$ \\
\hline & Mean lpg (SD) & $26^{\mathrm{a}}(11)$ & $49^{\mathrm{a}}(48)$ & $64^{\mathrm{a}}(66)$ \\
\hline & $\%$ of larval development & 17.5 & 24.7 & 32.9 \\
\hline
\end{tabular}

$2.5 \times 10^{5}$ group: goats receiving $2.5 \times 10^{5}$ chlamydospores $/ \mathrm{kg}$ BW/day.

$5 \times 10^{5}$ group: goats receiving $5 \times 10^{5}$ chlamydospores $/ \mathrm{kg} \mathrm{BW} /$ day.

The comparison was done between the groups at each date by parameter (epg or lpg).

a,b,c Different superscripts in a same row indicate a significant difference between the groups $(p<0.05)$.

in the control group was statistically lower $(p<0.05)$ than the egg excretion in the fungus group.

The larval production in the fungus group was statistically lower $(p<0.05)$ than in the control group from the 2nd day after the first administration of the chlamydospores until the 2nd day after the last administration. The reduction in percentage larval development due to $D$. flagrans ranged from 75.7 to $96.3 \%$ during this period.

\section{DISCUSSION}

The overall reductions ( 52 to $98 \%$ ) in the larval development of gastro-intestinal nematodes obtained in the present study with dose rates ranging from $1.25 \times 10^{5}$ to $5 \times 10^{5}$ chlamydospores $/ \mathrm{kg} \mathrm{BW} /$ day are in accordance with the results of previous studies in goats [17, 18, 24]. Paraud and
Chartier [17] and Paraud et al. [18] reported reductions higher than $80 \%$ of the larval development of Teladorsagia circumcincta or Trichostrongylus colubriformis after the administration of $5 \times 10^{5}$ chlamydospores/ $\mathrm{kg} \mathrm{BW/day} \mathrm{when} \mathrm{compared} \mathrm{to} \mathrm{the} \mathrm{control.}$ In the same way, in a plot study, after the administration of chlamydospores at a dose rate of $2.5 \times 10^{5} / \mathrm{kg} \mathrm{BW/day} \mathrm{to} \mathrm{goats,}$ Chartier and Pors [4] showed reductions in larval numbers of $T$. circumcincta or $T$. colubriformis ranging from 50 to $93 \%$ compared to the control according to the month of faecal deposit on the pasture.

There was no constant response to dose rate shown in the current studies: the reduction in larval recoveries were respectively 75,52 and $81 \%$ when increasing the chlamydospore dose rate from 1.25 to $5 \times 10^{5} / \mathrm{kg}$ $\mathrm{BW} /$ day compared to the control whereas this reduction ranged from 84 to $98 \%$ for 
Table IV. Mean number of eggs per gram (epg) of faeces, mean number of larvae per gram (lpg) of faeces and percentage of larval development obtained after coproculture $\left(14\right.$ days, $\left.25^{\circ} \mathrm{C}\right)$ at different dates before (d1), during (d2 to $\mathrm{d} 5$ ) and after (d6 to d10) administration of $5 \times 10^{5}$ chlamydospores/ $\mathrm{kg}$ BW/day to two groups of $T$. colubriformis infected goats (fungus: 4 animals; control: 3 animals).

\begin{tabular}{|c|c|c|c|c|c|}
\hline & & $\begin{array}{l}\text { Mean number } \\
\text { of epg }\end{array}$ & $\begin{array}{l}\text { Mean number } \\
\text { of lpg }\end{array}$ & $\begin{array}{l}\text { Mean larval } \\
\text { development }\end{array}$ & $\%$ of reduction \\
\hline \multirow[t]{2}{*}{$\mathrm{d} 1$} & Fungus & $213^{a}$ & $57^{\mathrm{a}}$ & 26.7 & \\
\hline & Control & $189^{\mathrm{a}}$ & $56^{\mathrm{a}}$ & 29.5 & \\
\hline \multirow[t]{2}{*}{$\mathrm{d} 2$} & Fungus & $258^{\mathrm{a}}$ & $27^{\mathrm{a}}$ & 10.6 & \\
\hline & Control & $159^{\mathrm{b}}$ & $47^{\mathrm{a}}$ & 29.8 & \\
\hline \multirow[t]{2}{*}{$\mathrm{d} 3$} & Fungus & $213^{\mathrm{a}}$ & $18^{\mathrm{a}}$ & 8.6 & \multirow[b]{2}{*}{91.4} \\
\hline & Control & $139^{\mathrm{a}}$ & $139^{b}$ & 99.7 & \\
\hline \multirow[t]{2}{*}{$\mathrm{d} 4$} & Fungus & $263^{\mathrm{a}}$ & $7^{\mathrm{a}}$ & 2.8 & \multirow{2}{*}{96.3} \\
\hline & Control & $189^{\mathrm{a}}$ & $142^{b}$ & 75.2 & \\
\hline \multirow[t]{2}{*}{ d5 } & Fungus & $246^{\mathrm{a}}$ & $21^{\mathrm{a}}$ & 8.6 & \multirow{2}{*}{90.7} \\
\hline & Control & $156^{\mathrm{a}}$ & $144^{\mathrm{b}}$ & 92.7 & \\
\hline \multirow[t]{2}{*}{ d6 } & Fungus & $238^{\mathrm{a}}$ & $4^{\mathrm{a}}$ & 1.8 & \multirow{2}{*}{92.8} \\
\hline & Control & $306^{\mathrm{a}}$ & $76^{\mathrm{b}}$ & 24.9 & \\
\hline \multirow[t]{2}{*}{$\mathrm{d} 7$} & Fungus & $225^{\mathrm{a}}$ & $34^{\mathrm{a}}$ & 15 & \multirow{2}{*}{75.7} \\
\hline & Control & $176^{\mathrm{a}}$ & $108^{\mathrm{b}}$ & 61.7 & \\
\hline \multirow[t]{2}{*}{$\mathrm{d} 8$} & Fungus & $242^{\mathrm{a}}$ & $164^{\mathrm{a}}$ & 68.0 & \\
\hline & Control & $213^{\mathrm{a}}$ & $165^{\mathrm{a}}$ & 77.1 & \\
\hline \multirow[t]{2}{*}{ d9 } & Fungus & $210^{\mathrm{a}}$ & $116^{\mathrm{a}}$ & 54.9 & \\
\hline & Control & $154^{\mathrm{a}}$ & $79^{\mathrm{a}}$ & 51.1 & \\
\hline \multirow[t]{2}{*}{$\mathrm{d} 10$} & Fungus & $213^{\mathrm{a}}$ & $73^{\mathrm{a}}$ & 34.2 & \\
\hline & Control & $128^{a}$ & $82^{\mathrm{a}}$ & 64.5 & \\
\hline
\end{tabular}

dX: day of administration of the fungus. Fungus: group of goats receiving the spores; control: group of goats not receiving the spores.

$\mathrm{a}, \mathrm{b}$ Different superscripts in the same column at the same date indicate a statistical difference between the fungus and the control group $(p<0.05)$. In this case, the larval development reduction is indicated.

2.5 and $5 \times 10^{5}$ chlamydospores/kg BW/day respectively in naturally infected goats during the field study. This apparent lack of a dose effect was also reported in previous works. In laboratory conditions, Peña et al. [19], by administering chlamydospore doses from $2.5 \times 10^{4}$ to $5 \times 10^{5} / \mathrm{kg} \mathrm{BW}$ per day to sheep, obtained reductions of the larval development of $H$. contortus from 76.6 to $100 \%$ without a significant difference between the doses by comparison with a control group. Similarly, Terrill et al. [23] when using the same range of chlamydospore dose rates in goats observed reductions in Haemonchus L3 development varying from 80.2 to $93.6 \%$ without any clear trend. Moreover, at the same dose rate $\left(2.5 \times 10^{5}\right.$ chlamydospores/kg BW/day) in two consecutive experiments, these authors found a larval reduction ranging from 54.8 to $80.2 \%$. On the contrary, Waghorn et al. [24] reported a dose response effect in sheep and goats 
only with $T$. circumcincta but not with $H$. contortus or $T$. colubriformis. One of the main reasons of this weak dose response effect found by several authors is probably the poor estimation of the larval development. Helminth eggs are not evenly distributed in the faeces [22] and when using a McMaster flotation technique on replicate faecal samples, the coefficient of variation of the mean number of eggs per gram may range from 22 to $270 \%$ [15]. Thus the estimate of mean eggs per gram may be, to some extent, different from the true value that is later involved in coproculture. Such technical variations may also occur for the evaluation of developed infective larvae in faecal samples after coproculture using the Baermann technique. Lastly, the conditions of coproculture as well as those of faecal material storage prior to coproculture are crucial in terms of larval development [9, 13]. Although some culture conditions such as temperature and humidity were standardised in our study, other uncontrolled biotic or abiotic factors, like the consistency of faeces and thus oxygenation for example, may have influenced the larval development and the variability. In such a situation, it could be expected that small differences in larval development for a relatively narrow range of chlamydospore dose rates was not assessed.

When the efficacy of $D$. flagrans was evaluated through the clinical consequences of nematode infection in grazing calves, the dose rate of $2.5 \times 10^{5}$ was generally reported as not satisfactory except in situations of very low infective larval challenge $[8,21]$. A dose rate of $5 \times 10^{5}$ or even $10^{6}$ chlamydospores $/ \mathrm{kg}$ BW/day was needed to achieve a steady control of clinical parasitism of calves at the beginning of the grazing season particularly with high stocking rates $[8,21]$. In small ruminants, a dose rate of $5 \times 10^{5}$ or more was recorded to allow lower infectivity of pasture, lower nematode infection and better growth of animals compared to the control $[3,10]$. All these results clearly indicate that, to be used on farms, the fungal dose must be chosen after consideration of both pasture infectivity and stocking rate.

In our study, two ways of administration were used: two trials conducted in the laboratory used a forced administration of chlamydospores by oral dosing and the farm trial was designed with a voluntary ingestion of the chlamydospores in feed. Some authors have already demonstrated the variability in efficacy linked to variations in voluntary consumption. Knox and Faedo [11] offered D. flagrans chlamydospores grown on barley grains to 3 groups of 10 grazing lambs 5 days a week for 6 months. One group given the fungus obtained the same results as the control group not receiving the chlamydospores for both faecal egg counts and live weight gain, since they refused to eat all the fungi treated barley until the fourth month of experimentation while the two other treated groups receiving the same fungal dose performed better than the control group. This possible high variability in the voluntary ingestion may accentuate differences in efficacy between doses, differences that could remain undetectable in conditions of forced administration.

This last hypothesis may also explain the divergent results obtained between the various trials concerning the time needed for a significant reduction to occur. In farm conditions, ten days of administration were necessary to obtain a significant reduction. In contrast, in the laboratory trial where measures of larval reduction were made each day from the beginning of forced administration, the reduction of the larval development was significant from the 2 nd day of administration. Peña et al. [19] reported similar results: on the 2 nd day of administration of chlamydospores to lambs, the larval development reduction of $H$. contortus in faeces reached 80.9 to $99.9 \%$. Similarly, Mendoza de Gives et al. [14] reported significant reductions in the larval development of $H$. contortus in sheep faeces as early as $14 \mathrm{~h}$ after the administration of $D$. flagrans.

The decline in larval reduction was noticed within two days after spore feeding 
ceased and was in agreement with the results of Peña et al. [19]. When comparing a daily versus every second or third day feeding of $D$. flagrans to goats, Terrill et al. [23] showed that the average larval reduction decreased from 54.8 to $20-22 \%$ respectively. This strongly suggests that daily feeding of chlamydospores is essential to maintain a steady reduction in the larval emergence. If this administration scheme is easy for dairy animals, it may be necessary to develop devices allowing a continuous release of chlamydospores for non-dairy ruminants. Waller et al. [27], when studying the development of fungal controlled release devices, have shown that viable chlamydospores are delivered in the faeces during three weeks and the larval development of $H$. contortus was reduced almost to zero. Another option tested by Chandrawathani et al. [2] was to incorporate chlamydospores into feed blocks. When the satisfactory consumption of blocks could be reached, reductions in larval emergence were similar to those obtained when chlamydospores were given in feed.

The results of these trials demonstrated that $D$. flagrans is highly and rapidly effective in controlling the larval development of gastro-intestinal nematodes in experimental conditions. Due to the variations observed in the efficiency, particularly in the farm conditions, the minimal dose to recommend appears to be $5 \times 10^{5}$ chlamydospores $/ \mathrm{kg}$ BW on a daily basis. Particular attention should be paid to the way of administration in order to limit variations in consumption: the chlamydospores must be distributed in a highly palatable feed or mineral mix with self-blocking feeding grills to ensure an individual access to feed as well as sufficient time to ingest the chlamydospores. Biological control represents a potentially effective option in the control of nematode parasitism and future control programmes should be designed to integrate biological options with the other available methods of control.

\section{ACKNOWLEDGEMENTS}

This experiment was supported by the European project FAIR QLK5-CT-2001-01843: "Worm control in organic production systems for small ruminants in Europe: towards the implementation of non-chemical, sustainable approaches", which is a collaboration between Denmark, Sweden, Spain, UK, The Netherlands and France. C. Paraud is a grateful recipient of a grant from AFSSA/Région Poitou-Charentes. We also thank Christian Hansen Ltd. for providing Duddingtonia flagrans chlamydospores.

\section{REFERENCES}

[1] Baudena M.A., Chapman M.R., Larsen M., Klei T.R., Efficacy of the nematophagous fungus Duddingtonia flagrans in reducing equine cyathostome larvae on pasture in south Louisania, Vet. Parasitol. 89 (2000) 219-230.

[2] Chandrawathani P., Jamnah O., Waller P.J., Larsen M., Gillespie A.T., Zahari W.M., Biological control of nematode parasites of small ruminants in Malaysia using the nematophagous fungus Duddingtonia flagrans, Vet. Parasitol. 117 (2003) 173-183.

[3] Chandrawathani P., Jamnah O., Adnan M., Waller P.J., Larsen M., Gillespie A.T., Field studies on the biological control of nematode parasites of sheep in the tropics, using the microfungus Duddingtonia flagrans, Vet. Parasitol. 120 (2004) 177-187.

[4] Chartier C., Pors I., Effect of the nematophagous fungus, Duddingtonia flagrans, on the larval development of goat parasitic nematodes: a plot study, Vet. Res. 34 (2003) 1-10.

[5] Chartier C., Pors I., Hubert J., Rocheteau D., Benoit C., Bernard N., Prevalence of anthelmintic resistant nematodes in sheep and goats in Western France, Small Rumin. Res. 29 (1998) 33-41.

[6] Chartier C., Soubirac F., Pors I., Silvestre A., Hubert J., Couquet C., Cabaret J., Prevalence of anthelmintic resistance in gastrointestinal nematodes of dairy goats under extensive management conditions in southwestern France, J. Helminthol. 75 (2001) 325-330.

[7] Euzéby J., Diagnostic expérimental des helminthoses animales, Tome 1 , Ministère de l'Agriculture, Informations Techniques des Services Vétérinaires, Paris, 1981, 349 p.

[8] Fernández A.S., Larsen M., Henningsen E., Nansen P., Grønvold J., Bjørn H., Wolstrup J., Effect of Duddingtonia flagrans against 
Ostertagia ostertagi in cattle grazing at different stocking rates, Parasitology 119 (1999) 105-111.

[9] Gevrey J., Les coprocultures: réalisation, interprétation en vue de la diagnose des Strongles digestifs des Ruminants et du Porc, Rech. Méd. Vét. 111 (1971) 287-317.

[10] Githigia S.M., Thamsborg S.M., Larsen M., Kyvsgaard N.C., Nansen P., The preventive effect of the fungus Duddingtonia flagrans on trichostrongyle infections of lambs on pasture, Int. J. Parasitol. 27 (1997) 931-939.

[11] Knox M.R., Faedo M., Biological control of field infections of nematode parasites of young sheep with Duddingtonia flagrans and effects of spore intake on efficacy, Vet. Parasitol. 101 (2001) 155-160.

[12] Knox M.R., Josh P.F., Anderson L.J., Deployment of Duddingtonia flagrans in an improved pasture system: dispersal, persistence, and effects of free-living soil nematodes and microarthropods, Biological Control 24 (2002) 176182.

[13] McKenna P.B., The effect of previous cold storage on the subsequent recovery of infective third stage nematode larvae from sheep faeces, Vet. Parasitol. 80 (1998) 167-172.

[14] Mendoza de Gives P., Flores Crespo J., Herrera Rodriguez D., Vazquez Prats V., Liebano Hernandez E., Ontiveros Fernandez G.E., Biological control of Haemonchus contortus larvae in ovine faeces by administering an oral suspension of Duddingtonia flagrans chlamydospores to sheep, J. Helminthol. 72 (1998) 343-347.

[15] Mes T.H.M., Technical variability and required sample size of helminth egg isolation procedures, Vet. Parasitol. 115 (2003) 311-320.

[16] Nansen P., Larsen M., Roepstorff A., Grønvold J., Wolstrup J., Henriksen S.A., Control of Oesophagostomum dentatum and Hyostrongylus rubidus in outdoor-reared pigs by daily feeding with the micro-fungus Duddingtonia flagrans, Parasitol. Res. 82 (1996) 580-584.

[17] Paraud C., Chartier C., Biological control of infective larvae of a gastro-intestinal nematode (Teladorsagia circumcincta) and a small lungworm (Muellerius capillaris) by Duddingtonia flagrans in goat faeces, Parasitol. Res. 89 (2003) 102-106.

[18] Paraud C., Pors I., Chartier C., Activity of Duddingtonia flagrans on Trichostrongylus colubriformis larvae in goat feces and interaction with a benzimidazole treatment, Small Rumin. Res. 55 (2004) 199-207.
[19] Peña M.T., Miller J.E., Fontenot M.E., Gillespie A., Larsen M., Evaluation of Duddingtonia flagrans in reducing infective larvae of Haemonchus contortus in faeces of sheep, Vet. Parasitol. 103 (2002) 259-265.

[20] Raynaud J.P., Étude de l'efficacité d'une technique de coproscopie quantitative pour le diagnostic de routine et le contrôle des infestations parasitaires des bovins, ovins, équins et porcins, Ann. Parasitol. Hum. Comp. 45 (1970) 321-342.

[21] Šarkūnas M., Larsen M., Nansen P., Hansen J.W., Biological control of trichostrongylid infections in calves on pasture in Lithuania using Duddingtonia flagrans, a nematodetrapping fungus, J. Helminthol. 74 (2000) 355-359.

[22] Schillhorn van Veen T.W., Methods for diagnosis of parasitism in small ruminants, Vet. Clin. North Am. Food Anim. Pract. 2 (1986) 335-344.

[23] Terrill T.H., Larsen M., Samples O., Husted S., Miller J.E., Kaplan R.M., Gelaye S., Capability of the nematode-trapping fungus $\mathrm{Dud}$ dingtonia flagrans to reduce infective larvae of gastro-intestinal nematodes in goat faeces in the southeastern United States: dose titration and dose time interval studies, Vet. Parasitol. 120 (2004) 285-296.

[24] Waghorn T.S., Leathwick D.M., Chen L.Y., Skipp R.A., Efficacy of the nematode-trapping fungus Duddingtonia flagrans against three species of gastro-intestinal nematodes in laboratory faecal cultures from sheep and goats, Vet. Parasitol. 118 (2003) 227-234.

[25] Waller P.J., International approaches to the concept of integrated control of nematode parasites of livestock, Int. J. Parasitol. 29 (1999) 155-164.

[26] Waller P.J., Larsen M., Faedo M., Hennessy D.R., The potential of nematophagous fungi to control the free-living stages of nematode parasites of sheep: in vitro and in vivo studies, Vet. Parasitol. 51 (1994) 289-299.

[27] Waller P.J., Faedo M., Ellis K., The potential of nematophagous fungi to control the freeliving stages of nematode parasites of sheep: towards the development of a fungal controlled release device, Vet. Parasitol. 102 (2001) 299-308.

[28] Yeates G.W., Dimander S.O., Waller P.J., Höglund J., Environmental impact on soil nematodes following the use of the ivermectin sustained-release bolus or the nematophagous fungus Duddingtonia flagrans to control nematode parasites of cattle in Sweden, Acta Agric. Scand. Sect. A Anim. Sci. 52 (2002) 233-242. 